\title{
Impact of Interfacial Characteristics on Foam Structure: Study on Model Fluids and at Pilot Scale
}

\author{
Samir Mezdour*, Eugénie Séguineau de Préval, Pablo Granda, Gérard Cuvelier \\ and Fabrice Ducept \\ UMR Ingénierie Procédés Aliments, AgroParisTech, INRA, Université Paris-Saclay, 1 avenue des Olympiades, 91300 Massy - France \\ e-mail: samir.mezdour@agroparistech.fr \\ * Corresponding author
}

\begin{abstract}
Foams represent an important area of research because of their relevance to many industrial processes. In continuous foaming operations, foaming ability depends on the process parameters and the characteristics of the raw materials used for foamed products. The effects of fluid viscosity and equilibrium surface tension on foam structure have been studied extensively. Furthermore, as surface active agents diffuse to the interface, they can modify other interface properties through their adsorption, such as interfacial rheology and surface tension kinetics. In order to better understand how these two interfacial properties influence foam structuring, we formulated model foaming solutions with different interface viscoelasticity levels and adsorption rates, but all with the same equilibrium surface tension and viscosity. The solutions were made up of a surface active agent and glucose syrup, so as to maintain a Newtonian behaviour. Five surface active agents were used: Whey Protein Isolate (WPI), sodium caseinate, saponin, cetyl phosphate and Sodium Dodecyl Sulphate (SDS), at concentrations ranging from $0.1 \%$ to $1 \%$. Their molecular characteristics, and their interaction with the glucose syrup, made it possible to obtain a range of interface viscoelasticities and surface tension kinetics for these model solutions. The solutions were whipped in a continuously-operating industrial foaming device in order to control process parameters such as shearing and overrun, and to ensure that the experiment was representative of industrial production. The structure of the foams thus obtained foams was then determined by characterising bubble size using image analysis. For all the model solutions, both the viscoelastic moduli and apparent diffusion coefficient were linked to foam structure. The results showed that both high interface viscoelasticity and rapid diffusion kinetics induced a foam structure containing small bubbles. Both effects, as well as the impact of the shearing rate, through the rotor speed, were then integrated in a predictive model for bubble size.
\end{abstract}

Résumé - Effets des propriétés interfaciales sur la structuration de mousses : étude sur produits modèles et à l'échelle pilote - Les mousses représentent un domaine de recherche important en raison de leur pertinence dans de nombreux procédés industriels. Dans l'opération de foisonnement en continu, la capacité moussante dépend des paramètres du procédé et les caractéristiques des matières premières utilisées. L'effet de la viscosité du fluide et de la tension superficielle à l'équilibre sur la structure de la mousse a été largement étudié. Cependant, lorsque les agents tensio-actifs diffusent aux interfaces, ils s'y adsorbent et modifient ainsi les autres propriétés de l'interface, en particulier la rhéologie interfaciale et la cinétique de tension superficielle. Afin de mieux comprendre comment ces propriétés interfaciales influent sur la structuration de la mousse, nous avons formulé des solutions 
modèles avec différents niveaux de viscoélasticité d'interface et différentes cinétiques d'absorption, mais ayant toutes la même tension de surface à l'équilibre et la même viscosité. Les solutions sont composées de sirop de glucose et d'un agent tensio-actif, afin de maintenir un comportement newtonien. Cinq agents tensio-actifs ont été utilisés : isolat protéique de lactosérum, caséinate de sodium, saponine, céthyle phosphate et Sodium Dodecyl Sulfate (SDS), à des concentrations variant entre $0.1 \%$ et $1 \%$. Les caractéristiques moléculaires et leur interaction avec le sirop de glucose ont permis d'obtenir une gamme de valeurs de viscoélasticité et de cinétique. Les solutions ont été foisonnées dans un équipement industriel continu de type rotor-stator, afin de contrôler les paramètres du procédé, principalement le cisaillement et le taux de foisonnement, et de façon à être représentatif des productions industrielles. La structure des mousses obtenues a été analysée par caractérisation de la taille des bulles, obtenue par analyse d'image. Pour toutes les solutions modèles, on montre que le module de viscoélasticité et le coefficient de diffusion ont un impact sur la structure de mousse. Des valeurs élevées de ces deux caractéristiques de l'interface favorisent la structuration de la mousse par des bulles de plus petite taille. L'impact de ces deux paramètres, ainsi que l'incidence du taux de cisaillement, pris en compte avec la vitesse du rotor, ont été intégrés dans un modèle de prédiction de taille de bulle.

\section{NOTATIONS}

$\begin{array}{ll}t & \text { Time (s) } \\ \sigma_{t} & \text { Surface tension at time } t\left(\mathrm{~N} \mathrm{~m}^{-1}\right) \\ \sigma_{0} & \text { Surface tension at } 0 \mathrm{~s}\left(\mathrm{~N} \mathrm{~m}^{-1}\right) \\ \sigma_{1 \mathrm{~s}} & \text { Surface tension at one second }\left(\mathrm{N} \mathrm{m}^{-1}\right) \\ \sigma_{\mathrm{eq}} & \text { Surface tension at equilibrium }\left(\mathrm{N} \mathrm{m}^{-1}\right) \\ t r & \text { Reorganization time (s) } \\ k_{\mathrm{diff}} & \text { Apparent diffusion coefficient }\left(\mathrm{N} \mathrm{m}^{-1} \mathrm{~s}^{-1 / 2}\right) \\ E^{*} & \text { Viscoelastic modulus }\left(\mathrm{N} \mathrm{m}^{-1}\right) \\ E^{\prime} & \text { Elastic modulus }\left(\mathrm{N} \mathrm{m} \mathrm{m}^{-1}\right) \\ E^{\prime \prime} & \text { Viscous modulus }\left(\mathrm{N} \mathrm{m} \mathrm{m}^{-1}\right) \\ d_{32} & \text { Sauter diameter (m) } \\ N & \text { Rotor speed (rpm) } \\ D & \text { Rotor diameter }(\mathrm{m}) \\ \mathrm{g} & \left.\text { Gravity (m s } \mathrm{m}^{-2}\right) \\ \rho & \left.\text { Bulk density (kg m }{ }^{-3}\right) \\ \eta & \text { Bulk viscosity (Pa s) } \\ a_{0}-a_{6}, b_{0}-b_{3} & \text { Constants (dimensionless) }\end{array}$

\section{INTRODUCTION}

Foams are being increasingly used in cosmetics and food innovations as they are much appreciated by consumers [1]. This success is due to their particular organoleptic properties, which includes their texture, as the foam structure contributes to its properties. It is therefore important to understand and control the mechanisms that govern foam structuring, which is usually described by means of three elements: the gas volume fraction, mean bubble size and/or bubble size distribution. Foam is generated through the creation of interfaces and requires an important energy supply. This dispersed state is thermodynamically unstable as the surface in contact with two immiscible fluids tends to be as small as possible. Nevertheless, the use of surface active molecules facilitates the production of bubbles and prolongs their shelf life [2]. Two types of surface active molecules are described in the literature: macromolecules which migrate slowly to the interfaces, and surfactants which are small molecules that diffuse very rapidly toward the interfaces. These molecules act by decreasing surface tension at the interfaces and thus lead to a gain in affinity between the gas and continuous phase. This surface property is most commonly characterized by the surface tension at equilibrium, whose effect on foam structure has been clarified and predicted for industrial foaming conditions [3, 4]. The importance of surface tension kinetics to foam structuring has also been widely studied. Some authors have shown that rapidly falling surface tensions will produce smaller bubbles at the laboratory scale [5-8]. These results were also confirmed with respect to industrial whipping devices [9].

Moreover, studies on $\beta$-lactoglobulin in various environmental conditions $(\mathrm{pH}$, ionic force, protein concentration, presence of polysaccharides) have revealed the effect of these viscoelastic interface properties on foam structure at a laboratory scale. Schmitt et al. [10] showed that high elastic modules led to bubbles of a more homogeneous size. In the same way, Perez et al. [11] demonstrated the effect of these modules on the foaming capacities of solutions. Dickinson [12] and Wilde [13] mentioned that when surface active species form an elastic and rigid interface around a bubble (like proteins), the bubble is able to better resist external solicitations.

To our knowledge, these results have not yet been confirmed under industrial conditions, and it is not easy to 
extrapolate laboratory findings because the processes are quite different. At the lab scale, foam is usually obtained in batches, whereas industrial processes are generally continuous and the gas volume fraction and product temperature can easily be controlled. Most studies conducted at the pilot scale have focused on the effect of operating variables [14-18], but rarely on the impact of interfacial properties. The opportunities to change and drive their levels are more limited than at the lab scale: for economic reasons the ingredients used are less pure and are processed without undergoing specific treatments (hydrolysis, $\mathrm{pH}$ or ionic force adjustment).

The objective of this work was therefore to quantify the effect of surface tension kinetics and interface rheology on the structure of foam generated using industrial devices, regardless of the nature of the surface active agent used. To achieve this, model solutions presenting the same bulk viscosity and surface tension at equilibrium but with distinct interface viscoelasticities and surface tension kinetics were formulated and whipped at the pilot scale in an industrial rotor-stator device. A previous study on the foaming operation had used a dimensional approach to reach a better understanding of the process and to develop a predictive model for bubble size based on surface tension at equilibrium, bulk viscosity and rotor speed [4]. As this modeling method was successful, we used the same method to include the effects of the aforementioned properties in a predictive model.

\section{MATERIALS AND METHODS}

\subsection{Product Composition, Selection of the Surface Active Molecules and Product Preparation}

Experiments have been carried out using model fluids, in order to obtain simple and well-defined surface property behaviours with different surface active agents. The continuous phase of the model systems consisted in glucose syrup, microfiltrated water and one surface active agent. By adjusting glucose syrup concentration between $78 \%$ and $86 \%(\mathrm{w} / \mathrm{w})$ and the surface active agent concentration between $0.1 \%$ and $1 \%(\mathrm{w} / \mathrm{w})$, we were able to obtain Newtonian solutions with a fixed viscosity of $0.7 \mathrm{~Pa} \mathrm{~s}$, and a fixed tension surface at equilibrium of $50 \mathrm{mN} \mathrm{m}^{-1}$.

For each surface active molecule various concentrations have been studied. The selection criteria of the model solutions were as follows:

- dispersibility/solubility of the surface active molecule in glucose syrup;

- Newtonian behaviour;

- good foaming capacities: screening at lab scale was implemented in order to select model solutions adapted to this study. These pre-tests included foaming with a domestic mixer (Kitchen Aid K45SS, USA) for $1 \mathrm{~min}$ $15 \mathrm{~s}$ at maximum speed [10];

- foam stability;

- possible characterization of interfacial properties: surface tension kinetics and at equilibrium and interface viscoelasticity using a bubble tensiometer.

Two glucose syrups (Tereos Syral, France), with the same dry matter content $(80 \%)$ and with two different Dextrose Equivalent (DE) rates have been selected in order to generate various solution interfacial characteristics: Glucomat 560 with a DE equal to $43 \%$ and Glucoplus 361 with a DE equal to $60 \%$. The sugar-water system is of particular interest because sugars are commonly used as ingredients in many food systems. The presence of sugars may influence surface active agent functionalities such as solubility, foam formation and foam stability. As described by Guzey et al. [19], the sugar type and the concentration impact the interfacial properties of globular proteins.

Five surface active molecules were selected after the initial trials: Whey Protein Isolate (WPI), sodium caseinate, saponin, cetyl phosphate and Sodium Dodecyl Sulphate (SDS).

The WPI (Prolacta 90) and the sodium caseinate were purchased from Lactalis (France). Saponin was kindly provided by $L V M H$ Research, the cetyl phosphate was obtained from DSM (The Netherlands) and the SDS Sigma (USA).

The WPI, the sodium caseinate and the cetyl phosphate were first of all dispersed at $40{ }^{\circ} \mathrm{C}$ in the dilution water. This mix was then added to the glucose syrup. The SDS was added in the same way but at ambient temperature, while saponin was added at ambient temperature to the already diluted glucose syrup.

\subsection{Fluid and Foam Characterizations}

The model solutions have been characterized at $20{ }^{\circ} \mathrm{C}$ in terms of their flowing properties and certain interfacial properties.

The flow curves were determined on a MCR301 rheometer (Physica, Germany). The configuration used was a Couette body (gap: $1.134 \mathrm{~mm}$; length: $40.016 \mathrm{~mm}$ ) in order to verified the targeted Newtonian viscosity of $0.7 \pm 0.01 \mathrm{~Pa}$.

\subsubsection{Surface Tension Characterization}

The air/bulk surface tension was measured versus time for every solution implementing the rising drop method on an automated drop tensiometer (Tracker, Teclis-IT Concept, France). Measurements were based on the axisymmetric drop shape analysis of an air bubble in the solutions [20]. A droplet volume of $7 \mathrm{~mL}$ was used. The adsorption 


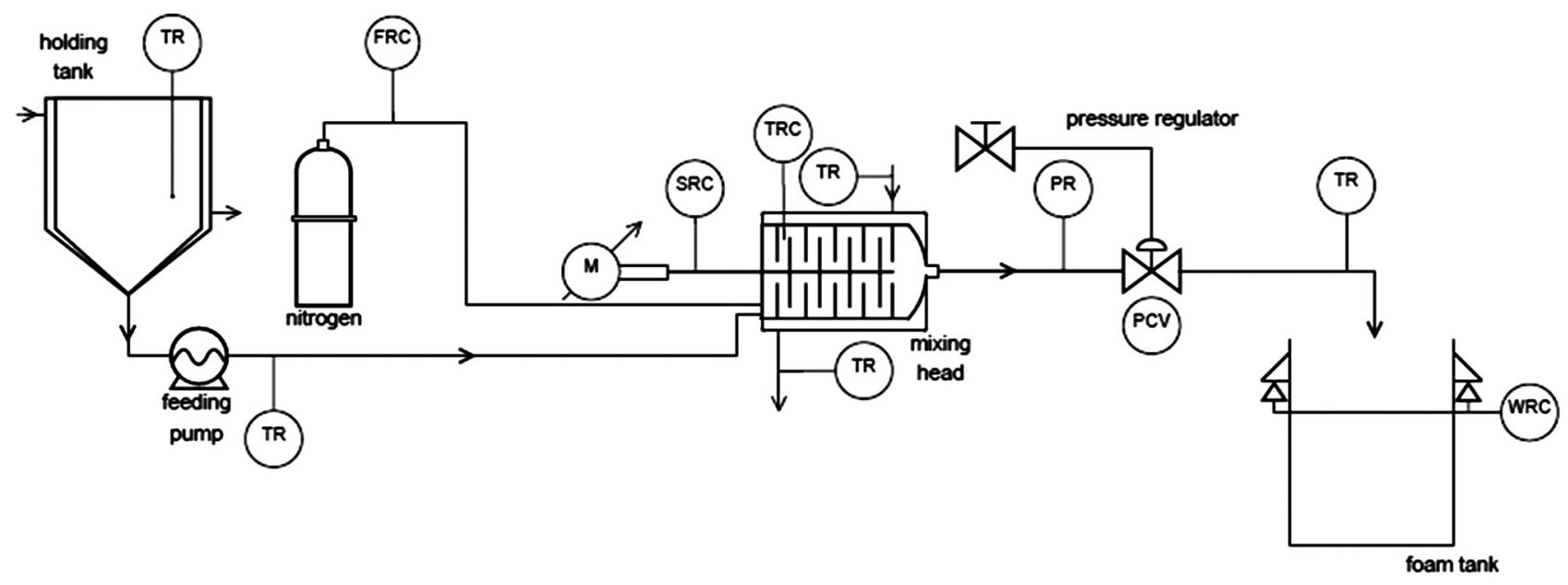

Figure 1

Diagram of the pilot-scale line: (C) control, (F) flow, (M) motor, (P) pressure, (R) recording, (S) speed, (T) temperature, (V) valve, (W) weight.

kinetics were recorded for at least $40 \mathrm{~min}$ at $20^{\circ} \mathrm{C} \pm 0.5^{\circ} \mathrm{C}$. The measurements were repeated at least three times and revealed a precision error of less than $0.5 \mathrm{mN} \mathrm{m}^{-1}$.

To enable quantitative comparison of the surface tension kinetics of model products, various descriptors have been defined in addition to the surface tension at equilibrium, $\sigma_{\text {eq. }}$. A previous study [10] proposed a choice of these relevant interface parameters: the reorganization time, tr, defined by Serrien et al. [21] (Eq. 1), and the apparent diffusion coefficient, $k_{\text {diff, }}$, described by Ward and Tordai [22] (Eq. 2):

$$
\sigma_{t}=\sigma_{\mathrm{eq}}+\Delta \sigma e^{-t / t r}
$$

where $\sigma_{t}$ is the surface tension value at time $t$ and $\Delta \sigma$ the total surface tension decrease.

$$
\sigma_{0}-\sigma_{t}=k_{\text {diff }} t^{1 / 2}
$$

where $\sigma_{0}$ is the surface tension value at time $t=0$.

The surface tension at one second, $\sigma_{1 \mathrm{~s}}$, has also been considered in order to take into account surface tension value at "short time"; even if one second could seem rather long according to process timescale, it corresponds to a compromise between the measurement precision and the time after formation.

\subsubsection{Interfacial Rheology Characterization}

Interface rheology measurements were performed using the same tensiometer. Sinusoidal fluctuations of the bubble area $(\mathrm{d} A / A)$ were applied at a chosen amplitudes and frequencies. Variations in surface tension $(\mathrm{d} \sigma)$ were recorded and compared with the deformation in order to determine the viscoelastic modulus $\left(E^{*}\right)$ of the interface (Eq. 3).

$$
E^{*}=\frac{\mathrm{d} \sigma}{\mathrm{d} A / A}=\frac{\mathrm{d} \sigma}{\mathrm{d}(\ln A)}
$$

The elastic component $E^{\prime}$ and the viscous component $E^{\prime \prime}$ were determined with the phase angle $\varphi$ between the deformation $\mathrm{d} A / A$ and the surface tension $\sigma$ using the following equations (Eqs. 4 and 5).

$$
\begin{aligned}
& E^{\prime}=E^{*} \cos \varphi \\
& E^{\prime \prime}=E^{*} \sin \varphi
\end{aligned}
$$

For purely elastic interfaces, $\mathrm{d} \sigma$ and $\mathrm{d} A / A$ are in phase $(\varphi=0)$, whereas for viscous interfaces $\varphi=90^{\circ}$. For the sinusoidal area fluctuations, the surface amplitude and the frequency were chosen in the linear domain and fixed respectively at $10 \%$ and at $0.02 \mathrm{~Hz}$.

\subsection{Foaming Process and Foam Characterization}

\subsubsection{Pilot Foaming Trials}

The solutions thus selected were then processed in a pilotscale line (Fig. 1). This consisted in a $12.5 \mathrm{~L}$ feed tank, a progressive cavity pump, and a rotor-stator mixer (MiniMondo, Haas-Mondomix, The Netherlands) which was equipped upstream with a gas injection inlet, and downstream with a back pressure valve. The mixing head used as a rotor had a volume of $0.3 \mathrm{~L}$. Various sensors and instruments placed along the process line allowed us to control the 
following operating parameters: product flow rate $(7.5 \mathrm{~kg} / \mathrm{h})$, rotor speed (500-1200 rpm) and back pressure (5 bar, absolute pressure). The temperature of the tank and the pipe feeding the mixing head was maintained at $20^{\circ} \mathrm{C}$ by a cryostat (1166D, VWR, USA). In the mixing head, the temperature was controlled in the same way, by means of a specific temperature sensor (PT 100, TC Direct, France) placed in it and connected to an ultracryostat (SL- FP51, Julabo, Germany), thus maintaining isothermal conditions. The nitrogen flow rate was adjusted to always ensure a $20 \%$ gas volume fraction in the foams at atmospheric pressure. As seen in previous studies $[4,9]$, because rotor speed is the most influential process parameter, it is the only to be changed.

\subsubsection{Gas Volume Fraction}

The gas volume fraction, $\Phi$, was checked systematically during process to ensure the correct implementation of the trials (i.e. incorporation of all the injected gas) using the following expression (Eq. 6), with $m_{\text {sol }}$ being the weight of fixed volume of solution, and $m_{\text {foam }}$ the weight of the same volume of foam.

$$
\Phi=\frac{m_{\mathrm{sol}}-m_{\mathrm{foam}}}{m_{\mathrm{sol}}}
$$

As described above, all foams had the same overrun and were produced at $\Phi=0.2$.

\subsubsection{Bubble Size Measurement}

Samples were collected at the exit of the pilot by filling some foam in small Petri dishes (Falcon, Becton Dickinson Labware, USA, $9 \times 50 \mathrm{~mm}$ ). A few snapshots per sample were taken just after 2-3 min later with a microscope (objectives at $\times 10$ and $\times 20$, BX61, Olympus, Germany) and a camera (Basler A102fc, Basler, Germany) in order to obtain a minimum of 500 bubbles and to ensure the statistical representativeness of the sample [4]. An automated image analysis procedure developed in our laboratory using Image J (version 1.42q) and Matlab (version 7.9.0.529, MathWorks, USA) made it possible to quantify the bubble size distributions and Sauter diameter $\left(d_{32}\right)$ of foams at atmospheric pressure with an accuracy of $0.5 \mu \mathrm{m}$. Sauter diameter $\left(d_{32}\right)$ represented the equivalent diameter of a bubble with the same volume/surface ratio as all the bubbles in a particular sample. The $d_{32}$ at process pressure $p$ was calculated by assuming that foam expansion followed Boyle's law at the outflow (Eq. 7).

$$
d_{32}=d_{32}^{p_{\text {atm }}}\left(\frac{p_{\text {atm }}}{p}\right)^{1 / 3}
$$

where $p$ is the foaming pressure, $p_{\text {atm }}$, the atmospheric pressure, $d_{32}$, the Sauter diameter calculated at process pressure, and $d_{32}^{p_{\text {atm }}}$, the mean bubble diameter measured.

\subsection{Modeling}

In order to dimension the impact of each previously described parameter, we proposed to use a dimensional analysis model. Indeed, a previous work had demonstrated the relevance of each approach to predicting mean bubble diameters on a pilot scale foaming device [4]. According to the method described by Delaplace et al. [23], for example, we assumed that the Sauter diameter at foaming pressure could be expressed as a function of the parameters relevant to the production of foam by rotor-stator mixers. The following Equation (8) thus represents the expression of $d_{32}$ according to a monomial relation form:

$$
\begin{aligned}
\frac{d_{32}}{D}= & a_{0}\left(\frac{D^{0.5} N}{\mathrm{~g}^{0.5}}\right)^{a_{1}}\left(\frac{E^{\prime}}{\rho D^{2} \mathrm{~g}}\right)^{a_{2}}\left(\frac{E^{\prime \prime}}{\rho D^{2} \mathrm{~g}}\right)^{a_{3}}\left(\frac{k_{\mathrm{diff}}}{\rho D^{1.75} \mathrm{~g}^{1.25}}\right)^{a_{4}} \\
& \times\left(\frac{\sigma_{1 \mathrm{~s}}}{\rho D^{2} \mathrm{~g}}\right)^{a_{5}}\left(\frac{\operatorname{trg}^{0.5}}{D^{0.5}}\right)^{a_{6}}
\end{aligned}
$$

where $D$ is the rotor diameter, $N$ the rotor speed, g the gravity, $\rho$ the bulk density, $E^{\prime}$ and $E^{\prime \prime}$ respectively the elastic and the viscous modulus of the interface, $k_{\text {diff }}$ the apparent diffusion coefficient, $\sigma_{1 \mathrm{~s}}$ the surface tension at one second, and $t r$ the reorganization time. Details on the method can be found in the article by Séguineau de Préval et al. [24].

The coefficient $a_{0}$ and the exponents $a_{1}-a_{6}$ were determined by fitting Equation (8) to the data obtained during our model experiments, using multiple regression.

\section{RESULTS AND DISCUSSION}

\subsection{Characterization of the Surface Properties of Model Solutions}

Using the method described above, nine model solutions have been selected, with a Newtonian viscosity of $0.7 \mathrm{~Pa} \mathrm{~s}$ $( \pm 0.01 \mathrm{~Pa} \mathrm{~s})$ and an equilibrium surface tension of $52 \mathrm{mN} \mathrm{m}^{-1}\left( \pm 2 \mathrm{mN} \mathrm{m}^{-1}\right.$; Tab. 1). The diversity of these model solutions concerning their surface properties and their descriptors is depicted in Table 1 and Figure 2.

Their kinetical profiles were rather different, which was subsequently taken in account in the modeling step (Fig. 2). For instance, the solution 5 lowered the surface tension very rapidly to $55 \mathrm{mN} \mathrm{m}^{-1}$ whereas this value was only achieved with the solution 4 after about $40 \mathrm{~min}$ $(2400 \mathrm{~s})$; some other solutions displayed intermediate surface tension kinetics (e.g. solution 9: $55 \mathrm{mN} \mathrm{m}^{-1}$ after $2 \mathrm{~min}$ ). The decreases follow different rates and surface tension at equilibrium tends to close $50 \mathrm{mN} \mathrm{m}^{-1}$.

This diversity of models can also be seen Figure 3, which reports the interfacial viscoelastic properties of each solution 
TABLE 1

Composition of the nine selected model solutions.

\begin{tabular}{|c|c|c|c|c|}
\hline \multirow{2}{*}{ Solution number } & \multicolumn{2}{|c|}{ Surface active agent } & \multicolumn{2}{|c|}{ Glycose syrup } \\
\hline & Nature & Conc. $(\% \mathrm{w} / \mathrm{w})$ & Nature & Conc. $(\% \mathrm{w} / \mathrm{w})$ \\
\hline 1 & WPI & 1 & Glucomat 560 & 84 \\
\hline 2 & WPI & 1 & Glucoplus 361 & 84 \\
\hline 3 & Caseinate & 1 & Glucomat 560 & 84 \\
\hline 4 & Caseinate & 1 & Glucoplus 361 & 84 \\
\hline 5 & Saponin & 0.13 & Glucomat 560 & 80.5 \\
\hline 6 & Saponin & 0.17 & Glucoplus 361 & 78.5 \\
\hline 7 & Cetyl phosphate & 0.3 & Glucoplus 361 & 85.35 \\
\hline 8 & SDS & 0.1 & Glucomat 560 & 85.7 \\
\hline 9 & SDS & 0.18 & Glucomat 560 & 85.7 \\
\hline
\end{tabular}

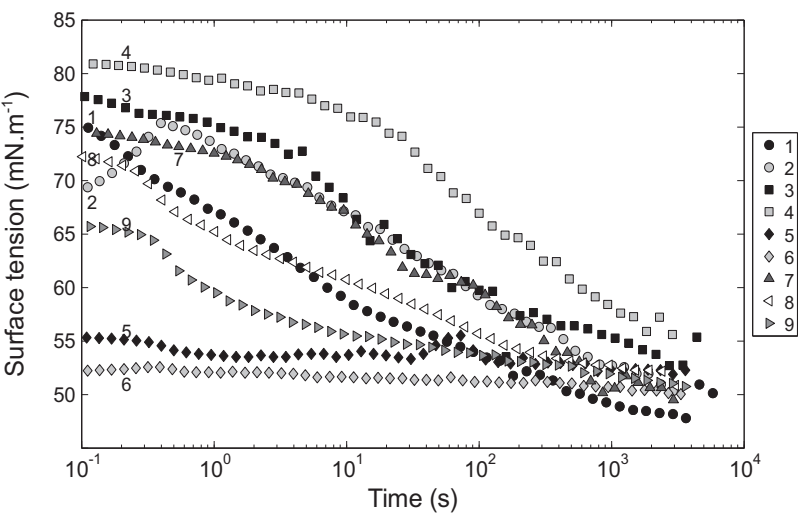

Figure 2

Comparison of surface tension kinetics of the nine model solutions.

versus the apparent diffusion coefficient. $E^{\prime}$ varying from 0.1 to $51 \mathrm{mN} \mathrm{m}^{-1}$, and $E^{\prime \prime}$, from 3 to $35 \mathrm{mN} \mathrm{m}^{-1}$. Moreover, according to these 9 solutions, one could achieve a rather large panel of properties: solutions 1, 2, 3, 7 had similar kinetic curves, but very different viscoelastic characteristics; conversely, solutions 5 and 9 showed similar viscoelastic characteristics, but different kinetics.

From these experimental measurements, we have reported the five interfacial parameters in Table 2.

\subsection{From Surface Properties to Foam Structure}

Model solutions were whipped at a pilot scale under operating conditions that were constant except for the rotor speed, which was varied from 500 to $1200 \mathrm{rpm}$. The foam samples were photographed just after processing. Image analysis performed on the snapshots allowed us to determine the bubble size distribution for each foam sample and therefore the mean bubble diameter $d_{32}$ (Fig. 4).

As can be seen from the graph, the model solution exerted an important effect, namely on the surface properties they gave to the foam structure. Bubble sizes were completely different from one model solution to another. Indeed, at $500 \mathrm{rpm}$, the bubble sizes vary from $18 \mu \mathrm{m}$ to $65 \mu \mathrm{m}$ depending on the solutions.

The effect of rotor speed is also observable on this graph (Fig. 4). The higher the rotor speed, the smaller the bubbles. This phenomenon has previously been described by numerous authors [4, 24-27]. High rotor speeds generate larger shear strains, which favor the splitting of bubbles, which were consequently smaller at higher rotor speeds.

These results suggest that, beyond the well-known equilibrium surface tension impact, surface tension kinetic and interfacial viscoelasticity have an effect on the bubble sizes [28-31].

In order to visualise the individual effect of surface tension kinetics or interface viscoelasticity of the foaming solutions, we represented the $d_{32}$ versus each of these characteristics (Fig. 5). The impact of the reorganization time, $t r$, is not clear on that graph. Concerning the four other parameters, the smaller the interfacial property, the bigger the bubbles.

According to a qualitative description, Figure 5 shows that high values of the viscoelastic modulus ( $E^{\prime}$ and $\left.E^{\prime \prime}\right)$ appear to induce smaller bubbles. In a previous work [9], it has been shown that high value of diffusion coefficient induces smaller 

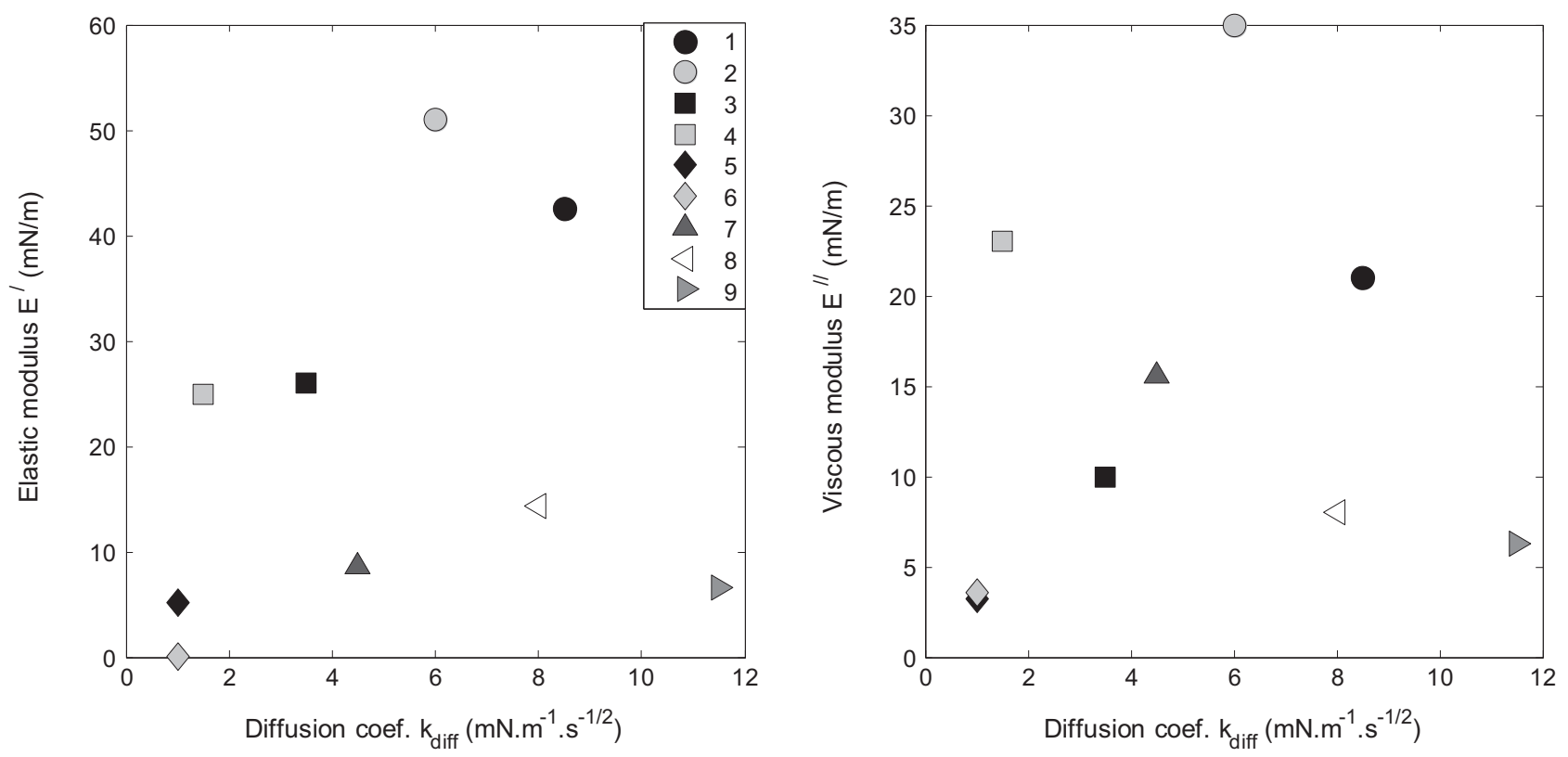

Figure 3

Interfacial properties of the nine model solutions.

TABLE 2

Interfacial properties of the nine selected model solutions.

\begin{tabular}{|c|c|c|c|c|c|}
\hline Solution number & $E^{\prime}\left(\mathrm{mN} \mathrm{m}^{-1}\right)$ & $E^{\prime \prime}\left(\mathrm{mN} \mathrm{m}^{-1}\right)$ & $k_{\mathrm{diff}}\left(\mathrm{mN} \mathrm{m}^{-1} \mathrm{~s}^{-1 / 2}\right)$ & $\sigma_{1 \mathrm{~s}}\left(\mathrm{mN} \mathrm{m}^{-1}\right)$ & $\operatorname{tr}(\mathrm{s})$ \\
\hline 1 & 42.6 & 21.0 & 8.5 & 67 & 618.3 \\
\hline 2 & 51.0 & 35.0 & 6.5 & 74 & 355.4 \\
\hline 3 & 26.0 & 10.0 & 3.5 & 75.4 & 830.6 \\
\hline 4 & 25.0 & 23.0 & 1.5 & 79 & 352.7 \\
\hline 5 & 5.2 & 3.2 & 1.0 & 53.7 & 555 \\
\hline 6 & 0.1 & 3.6 & 1.0 & 52 & 3531 \\
\hline 7 & 8.6 & 15.6 & 4.5 & 73 & 282 \\
\hline 8 & 14.4 & 8.0 & 8.0 & 65.4 & 137.8 \\
\hline 9 & 6.6 & 6.3 & 11.5 & 60 & 461.5 \\
\hline
\end{tabular}

bubble size. The results of the present study (Fig. 5) were almost consistent with this trend, as the steep slopes of the surface tension kinetic curve, represented by $k_{\text {diff, }}$ were linked to small bubbles. Nevertheless, the result also seemed to be inconsistent with those relative to surface tension at short time, where rapid surface tension kinetics corresponded to high $\sigma_{1 \mathrm{~s}}$ values but induced small bubbles. Furthermore, the impact of the reorganization time was not clear.
In order to achieve a quantitative analysis of these interfacial parameter impacts on foam structures, we implemented modeling using a dimensional analysis approach.

\subsection{Modeling}

Dimensional analysis was used during this study to quantify the effect of both operating and interface variables. 


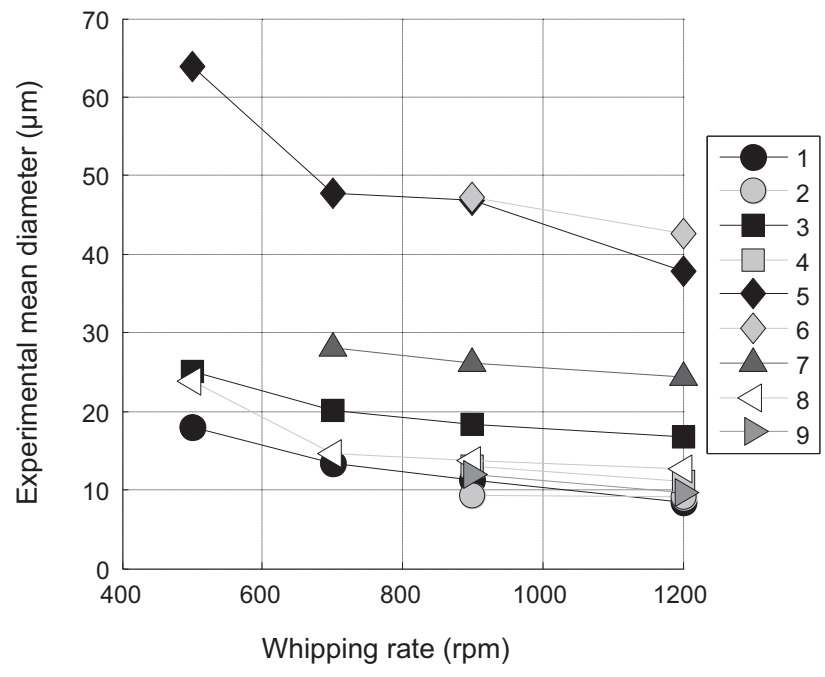

Figure 4

$d_{32}$ value for each model solution processed at different rotor speeds.
As mentioned in Section 1, Equation (8) was chosen to model their impacts on bubble size:

$$
\begin{aligned}
\frac{d_{32}}{D}= & a_{0}\left(\frac{D^{0.5} N}{\mathrm{~g}^{0.5}}\right)^{a_{1}}\left(\frac{E^{\prime}}{\rho D^{2} \mathrm{~g}}\right)^{a_{2}}\left(\frac{E^{\prime \prime}}{\rho D^{2} \mathrm{~g}}\right)^{a_{3}}\left(\frac{k_{\mathrm{diff}}}{\rho D^{1.75} \mathrm{~g}^{1.25}}\right)^{a_{4}} \\
& \times\left(\frac{\sigma_{1 \mathrm{~s}}}{\rho D^{2} \mathrm{~g}}\right)^{a_{5}}\left(\frac{\operatorname{trg}^{0.5}}{D^{0.5}}\right)^{a_{6}}
\end{aligned}
$$

The constant values and the statistics of the model are given in Table 3 and a graphical representation of the model is given in Figure 6.

Based on the data collected from our experiments, we could develop two different correlations.

The first one is described by this Equation (8). The statistics of the model 1 are given in Table 3. The $p$-values of rotor speeds $N$, elastic modulus $E^{\prime}$ and apparent diffusion

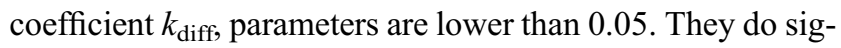
nificantly impact bubble size. As we can see in Figure 6
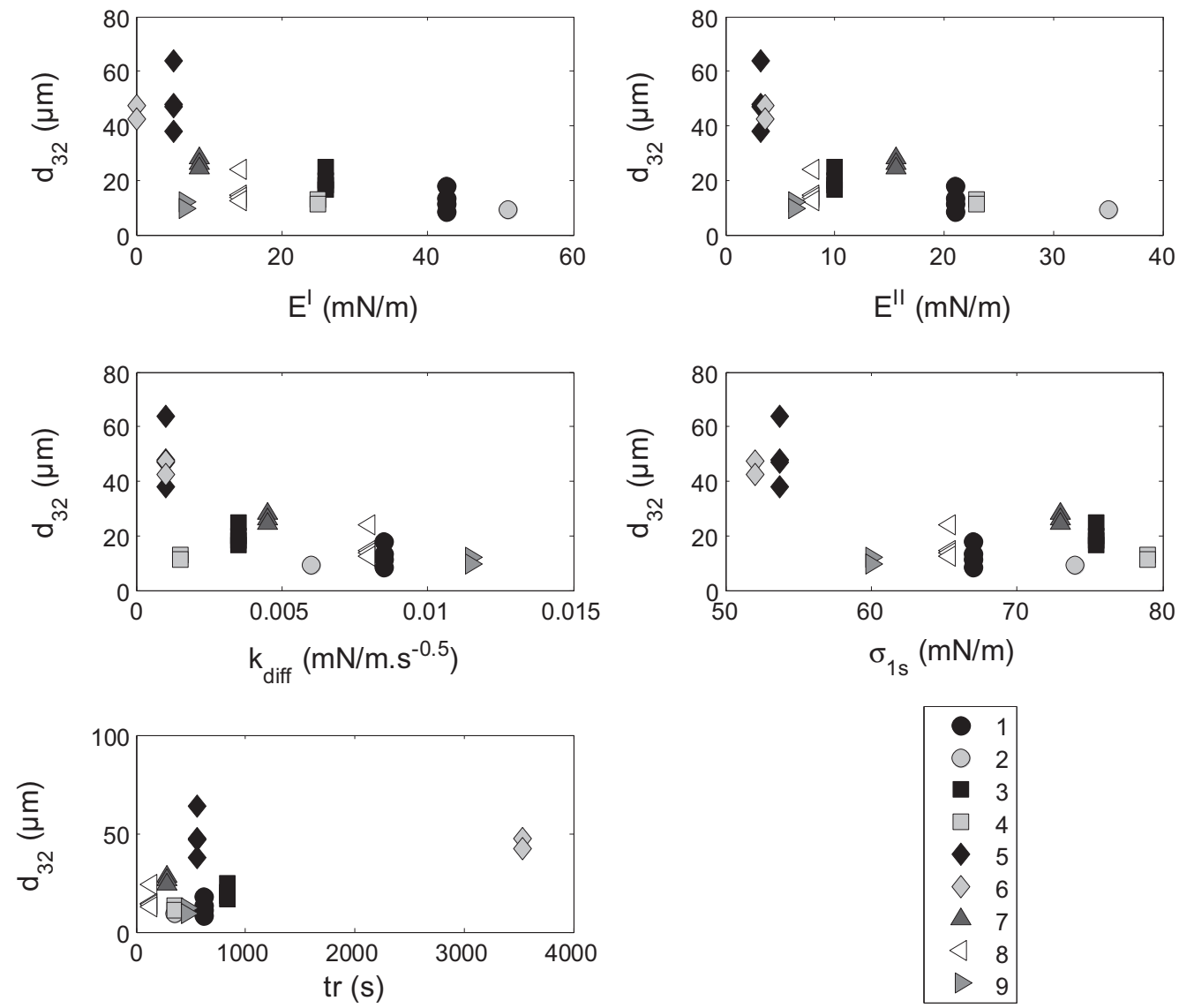

Figure 5

Evolution of mean bubble diameter versus the interfacial elastic modulus, $E^{\prime}$, the interfacial viscous modulus, $E^{\prime \prime}$, the apparent diffusion coefficient, $k_{\mathrm{diff}}$, the surface tension at one second $\sigma_{1 \mathrm{~s}}$ and the reorganization time, $t r$, of the model solutions. 
TABLE 3

Coefficient values and statistics for Equation $(8)-R^{2}=0.83$.

\begin{tabular}{c|c|c|c|c|c|c|c}
\hline Constant & $a_{0}$ & $a_{1}$ & $a_{2}$ & $a_{3}$ & $a_{4}$ & $a_{5}$ & $a_{6}$ \\
\hline Variable & & $N$ & $E^{\prime}$ & $E^{\prime \prime}$ & $k_{\text {diff }}$ & $\sigma_{1 \mathrm{~s}}$ & $t r$ \\
\hline Value & $7.45 \times 10^{-5}$ & -0.660 & -0.131 & -0.212 & -0.333 & 0.298 & -0.072 \\
\hline$p$-Value & $4.9 \times 10^{-14}$ & $2.3 \times 10^{-4}$ & 0.01 & 0.12 & $1.6 \times 10^{-4}$ & 0.67 & 0.34 \\
\hline
\end{tabular}

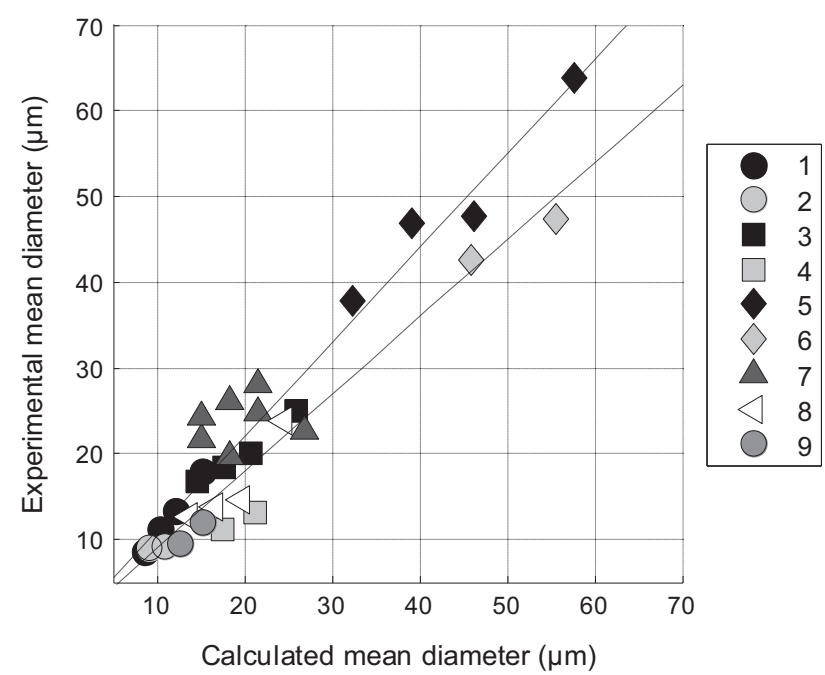

Figure 6

Experimental versus theoretical $d_{32}(\mu \mathrm{m})$ according to Equation (8).

which represents the experimental diameters versus the theoretical diameters, this relationship satisfactorily correlates experimental data.

Modeling enabled reasonably good predictability of mean bubble diameters, as shown by the coefficient of determination, $R^{2}=0.83$. Nevertheless, the $p$-values of three other parameters $\left(E^{\prime \prime}, \operatorname{tr}\right.$ and $\left.\sigma_{1 \mathrm{~s}}\right)$ being superior to 0.05 , they do not significantly impact bubble size. Thus, the effects of the interfacial elastic modulus, $E^{\prime \prime}$, the reorganization time, $t r$, and the surface tension at one second, $\sigma_{1 \mathrm{~s}}$, on foam structure were not statistically significant. Once we eliminate these three parameters, we get a second correlation:

$$
\frac{d_{32}}{D}=b_{0}\left(\frac{D^{0.5} N}{\mathrm{~g}^{0.5}}\right)^{b_{1}}\left(\frac{E^{\prime}}{\rho D^{2} \mathrm{~g}}\right)^{b_{2}}\left(\frac{k_{\mathrm{diff}}}{\rho D^{1.75} \mathrm{~g}^{1.25}}\right)^{b_{3}}
$$

Therefore, by not taking account of these two parameters, as described in Equation (9), we obtained results reported in Table 4 and Figure 7.

The predictability of this model was rather similar to that of the former model, as can be seen in Figure 7 and from the
TABLE 4

Coefficient values and statistics for Equation (9) $-R^{2}=0.79$.

\begin{tabular}{c|c|c|c|c}
\hline Constant & $b_{0}$ & $b_{1}$ & $b_{2}$ & $b_{3}$ \\
\hline Variable & & $N$ & $E^{\prime}$ & $k_{\text {diff }}$ \\
\hline Value & $3.64 \times 10^{-5}$ & -0.593 & -0.304 & -0.362 \\
\hline$p$-Value & $1.3 \times 10^{-2}$ & $9.3 \times 10^{-4}$ & $7.4 \times 10^{-4}$ & $2.2 \times 10^{-5}$ \\
\hline
\end{tabular}

coefficient of determination, at $R^{2}=0.79$. Removing the non-significant parameters decreases the accuracy from $84 \%$ to $79 \%$ which remains acceptable.

As a consequence, interfacial viscoelasticity, as described by the viscoelastic modulus, and the surface tension kinetic, described by the diffusion coefficient, were strongly correlated with mean bubble diameters. It appears that these two parameters were sufficient, in part of this work, to take account of the impact of interfacial properties on foam structure. On the other hand, the surface tension during a short period and the reorganization time should not be expected to exert a clear effect in this situation.

Furthermore, as previously observed on Figure 4, Equation (9) shows that a high interfacial elastic level or a high interfacial apparent diffusion coefficient induces foam structures with small bubbles.

According to a previous work [4], one could propose a more physical relation, although all parameters were not variables, and therefore their effects could not be evaluated:

$$
\frac{d_{32}}{D}=3.2410^{-4}\left(\frac{\eta N D}{\sigma_{\mathrm{eq}}}\right)^{-1.44}\left(\frac{\eta N D}{E^{\prime}}\right)^{0.30}\left(\frac{\eta N^{1.5} D}{k_{\mathrm{diff}}}\right)^{0.36}
$$

with $R^{2}=0.79$. This relation is statistically equivalent to the previous Equation (9), and proposes the same exponents for the numbers related to $E^{\prime}$ and $k_{\text {diff. }}$ The three dimensionless numbers correspond to specific forms of capillary numbers, and express the ratio of the convective force to the interfacial force. 


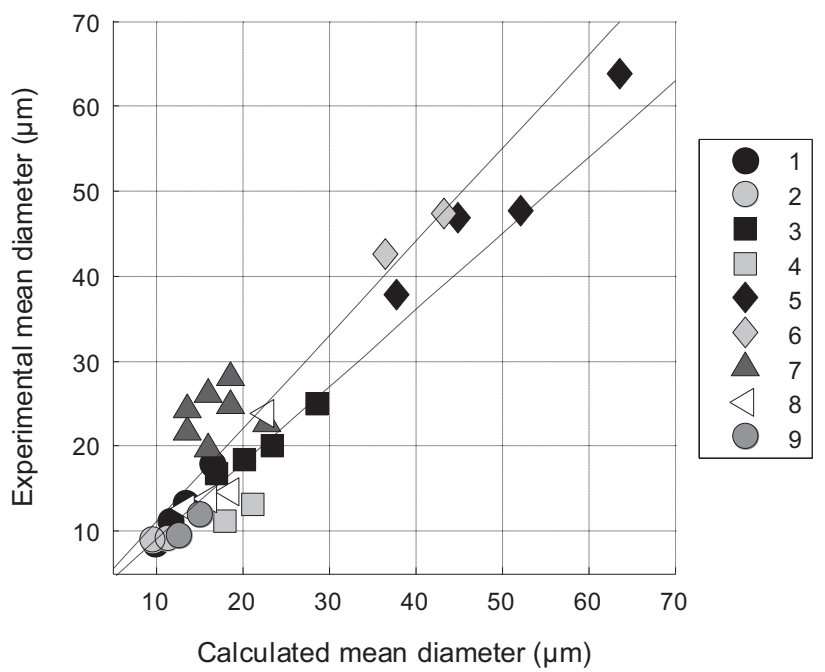

Figure 7

Experimental versus theoretical $d_{32}(\mu \mathrm{m})$ according to Equation (9).

\section{CONCLUSION}

The objective of this work was to quantify the effects of surface tension kinetics and interface rheology on the structure of foam generated using industrial devices. To achieve this, model solutions presenting the same bulk viscosity $(0.7 \mathrm{~Pa} \mathrm{~s})$ and surface tension at equilibrium $\left(50 \mathrm{mN} \mathrm{m}^{-1}\right)$ but with distinct surface tension kinetics and interface viscoelasticities were formulated and whipped at a pilot scale. Five surface active molecules were chosen for this study: WPI, sodium caseinate, saponin, cetyl phosphate and SDS. The surface tension kinetics were also determined in order to assess their potential effect on bubble size. Rapid surface tension kinetics, as well as high interface viscoelasticities, appeared to favour the generation of small bubbles. The well-known effect of rotor speed could also been seen from the data collected. In order to quantify the individual effects of surface tension kinetics, interface viscoelasticity and rotor speed, a dimensional analysis was performed and led to the determination of a predictive model for bubble size.

Furthermore, differences between the theoretical and experimental values suggested that more properties probably need to be considered if we are to efficiently predict the structure of foam, and particularly the interfacial charge or phase angle.

In order to achieve a global modeling structure and be able to predict foam structure more widely, it would at least be necessary to integrate the two influential parameters highlighted here in the previous model proposed by Mary et al. [4]. Thus, as explained in that former study, it would possible to propose rearrangements of dimensionless numbers in order to reveal known numbers, and thus find a physical meaning for this new relationship. Further, experiments are needed and currently in progress. We intend to focus on the effect of other physico-chemical properties, of more complex bulk rheological behaviors with nonNewtonian model fluids and of another geometry device.

\section{ACKNOWLEDGMENTS}

We would like to thank $L V M H$ Research for their collaboration in this study.

\section{REFERENCES}

1 Kammesheidt K. (2003) Formulating aerated dairy foods: customized stabilizers prevent foams from collapsing, Dairy Foods 11, 38-40.

2 Kinsella J.E. (1980) Functionnal properties of proteins: possible relationships between structure and function in foams, Food Chem. 7, 273-288.

3 Narchi I., Vial C., Djelveh G. (2007) Influence of bulk and interfacial properties and operating conditions on continuous foaming operation applied to model media, Food Res. Int. 40, 1069-1079.

4 Mary G., Mezdour S., Delaplace G., Lauhon R., Cuvelier G., Ducept F. (2013) Modelling of the continuous foaming operation by dimensional analysis, Chem. Eng. Res. Des. 9, 1, 2579-2586.

5 Kitabake N., Doi E. (1988) Surface tension and foamability of protein and surfactant solutions, J. Food Sci. 53, 1542-1545.

6 Chen J., Dickinson E. (1995) Protein/surfactant interfacial interactions part 3. Competitive adsorption of protein + surfactant in emulsions, Colloids Surf. A., Physicochem. Eng. Aspects 101, 77-85.

7 Rodriguez Patino J.M., Miñones Conde J., Millán Linares H., Pedroche Jimenez J.J., Carrera Sanchez C., Pizones V., Millán Rodriguez F. (2007) Interfacial and foaming properties of enzyme-induces hydrolysis of sunflower protein isolate, Food Hydrocoll. 21, 782-793.

8 Martinez K.D., Carrera Sanchez C., Rodriguez Patino J.M., Pilosof A.M.R. (2009) Interfacial and foaming properties of soy protein and their hydrolysates, Food Hydrocoll. 23, 2149-2157.

9 Séguineau de Préval E., Ducept F., Cuvelier G., Mezdour S. (2014) Effect of bulk viscosity and surface tension kinetics on structure of foam generated at the pilot-scale, Food Hydrocoll. 14, 104-111.

10 Schmitt C., Palma da Silva T., Bovay C., Rami-Shojaei S., Frossard P., Kolodziejczyk E., Leser M. (2005) Effect of time on the interfacial and foaming properties of $\beta$-lactoglobulin/ acacia gum electrostatic complexes and coacervates at $\mathrm{pH}$ 4.2, Langmuir 21, 7786-7795.

11 Perez A.A., Carrera Sanchez C., Rodriguez Patino J.M., Rubiolo A.C., Santiago L.G. (2012) Foaming characteristics of $\beta$-lactoglobulin as affected by enzymatic hydrolysis and polysaccharide addition: relationships with the bulk and interfacial properties, J. Food Eng. 113, 53-60. 
12 Dickinson E. (1999) Adsorbed protein layers at fluid interfaces: interactions, structure and surface rheology, Colloids Surf. B.: Biointerfaces 15, 161-176.

13 Wilde P.J. (2000) Interfaces: their role in foam and emulsion behaviour, Curr. Opin. Colloid Interface Sci. 5, 76-181.

14 Thakur R.K., Vial C., Djelveh G. (2003) Influence of operating conditions and impeller design on the continuous manufacturing of food foams, J. Food Eng. 60, 9-20.

15 Drenckhan W., Saint-Jalmes A. (2015) The science of foaming, Adv. Colloid Interface Sci. 222, 228-259.

16 Müller-Fischer N., Suppiger D., Windhab E.J. (2007) Impact of static pressure and volumetric energy input on the microstructure of food foam whipped in a rotor-stator device, J. Food Eng. 80, 306-316.

17 Indrawati L., Narsiham G. (2008) Characterization of protein stabilized foam formed in a continuous shear mixing apparatus, J. Food Eng. 88, 456-465.

18 Narchi I., Vial C., Labbafi M., Djelveh G. (2011) Comparative study of the design of continuous aeration equipment for the production of food foams, J. Food Eng. 102, 105-114.

19 Guzey D., McClements D.J., Weiss J. (2003) Adsorption kinetics of BSA at air-sugar solution interfaces as affected by sugar type and concentration, Food Res. Int. 36, 649-660.

20 Benjamin J., Cagna A., Lucassen-Reynders E.H. (1996) Viscoelastic properties of triacylglycerol/water interfaces covered by proteins, Colloids Surf. A.: Physicochem. Eng. Aspects 114, 245-254.

21 Serrien G., Geeraerts G., Ghosh L., Joos P. (1992) Dynamic surface properties of adsorbed protein solutions: BSA, casein and buttermilk, Colloids Surf. 68, 219-233.

22 Ward A., Tordai L. (1946) Time dependence of boundary of solutions. I. The role of diffusion in time effect, J. Chem. Phys 14, 453-461.
23 Delaplace G., Loubière K., Ducept F., Jeantet R. (2015) Dimensional analysis of food processes, ISTE Press, London.

24 Séguineau de Préval E., Ducept F., Mary G., Cuvelier G., Mezdour S. (2014) Influence of surface properties and bulk viscosity on bubble size prediction during foaming operation, Colloids Surf. A.: Physicochem. Eng. Aspects 442, 88-97.

25 Hanselmann W., Windhab E. (1998) Flow characteristics and modelling of foam generation in a continuous rotor/stator mixer, J. Food Eng. 38, 393-405.

26 Balerin C., Aymard P., Ducept F., Vaslin S., Cuvelier G. (2007) Effect of formulation and processing factors on the properties of liquid food foams, J. Food Eng. 78, 802-809.

27 Kroezen A.B.J., Groot Wassink J. (1997) Bubble size distribution and energy dissipation in foam mixers, J. Soc. Dyers Colourists 103, 386-394.

28 Williams A., Prins A. (1996) Comparison of the dilatational behaviour of adsorbed milk proteins at the air-water and oilwater interfaces, Colloids Surf. A.: Physicochem. Eng. Aspects 114, 267-275.

29 Prins A. (1999) Stagnant surface behaviour and its effect on foam and film stability, Colloids Surf. A.: Physicochem. Eng. Aspects 149, 467-473.

30 Bos M.A., van Vliet T. (2001) Interfacial rheological properties of adsorbed protein layers and surfactants: a review, $A d v$. Colloid Interface Sci. 91, 437-471.

31 Graham D.E., Phillips M.C. (1976) The conformation of proteins at the air-water interface and their role in stabilizing foams, in: Akers R.J. (ed), Foams, Academic Press, London, pp. 195-215.

Manuscript submitted in October 2016

Manuscript accepted in March 2017 Published online in April 2017

Cite this article as: S. Mezdour, E. Séguineau de Préval, P. Granda, G. Cuvelier and F. Ducept (2017). Impact of Interfacial Characteristics on Foam Structure: Study on Model Fluids and at Pilot Scale, Oil Gas Sci. Technol 72, 13. 